\title{
AVALIAÇÃO DA QUALIDADE DE LINGÜIÇAS FRESCAIS MEDIANTE DETERMINAÇÃO DE HIDROXIPROLINA
}

\begin{abstract}
O presente estudo teve como objetivo estimar o teor de colágeno em lingüiças frescais do tipo toscana, comercializadas na região do Alto Uruguai Catarinense, a partir da determinação de hidroxiprolina. Foram analisadas amostras de três diferentes procedências, obtidas no comércio varejista da área em estudo. Os teores médios obtidos de hidroxiprolina e colágeno foram significativamente mais elevados $(p<0,05)$ nas amostras de lingüiças toscanas da procedência $\mathbf{A}$ quando comparadas com os resultados dos outros produtos analisados. Todas as amostras analisadas apresentaram baixos teores de hidroxiprolina em base seca com médias de 0,29\% (A), $0,20 \%$ (B) e $0,21 \%$ (C) e valores médios para o colágeno de $2,36 \%, 1,59 \%$ e $1,64 \%$, respectivamente. Os resultados demonstraram que as lingüiças toscanas pesquisadas apresentam boa qualidade, considerando os percentuais de hidroxiprolina, colágeno e umidade. Também podem ser consideradas de boa qualidade nutricional e quanto ao controle de processo, pois os valores obtidos na relação colágeno/proteína e de variabilidade são mais adequados que os divulgados pela literatura em trabalhos semelhantes. Entretanto, foi constatada a irregularidade do uso de proteína não-cárnea declarada na rotulagem das amostras de uma das procedências, sugerindo influência quanto aos resultados em relação a essas amostras e ineficiência do serviço de inspeção.
\end{abstract}

PALAVRAS-CHAVE: LINGUIÇA TOSCANA; COLÁGENO; HIDROXIPROLINA; QUALIDADE NUTRICIONAL.

* Bacharel em Química Industrial de Alimentos, Universidade do Contestado (UnC), Concórdia, SC (email: lua_stc@yahoo.com.br).

** Doutor em Química, UnC, Concórdia, SC (e-mail: joni@uncnet.br). 


\section{INTRODUÇÃO}

A produção de embutidos exige ampla variedade de ingredientes cárneos e não-cárneos, cada um exercendo função específica de acordo com suas propriedades. Os ingredientes cárneos podem ter diversas origens e composições, influenciando assim a qualidade do produto final.

A utilização de retalhos e cortes menos nobres em produtos cárneos processados, ricos em tecido conjuntivo, pode apresentar elevadas porcentagens de proteínas com baixo valor nutritivo, sobretudo de colágeno (REIS et al., 1999).

O colágeno (glicoproteína) apresenta quantidade relativamente elevada de hidroxiprolina (13 a 14\%), ao contrário de outras proteínas conhecidas. A determinação da concentração desse aminoácido pode então ser usada para estimar o teor de colágeno existente nos tecidos. Outros métodos têm sido estudados para a quantificação de colágeno, mas a determinação de hidroxiprolina ainda constitui a técnica mais adequada para misturas protéicas de produtos industrializados cárneos (PARDI et al., 2001; EGELANDSDAL et al., 2005).

Em torno de $65 \%$ do total da produção brasileira de carne suína destina-se ao mercado interno na forma de produtos industrializados (ABIPECS, 2006). Entre os produtos processados, a linguiça frescal do tipo toscana (constituída exclusivamente de carne suína) representa alternativa para o aproveitamento de cortes suínos menos nobres devido ao baixo custo de produção e grande aceitação pelo mercado consumidor.

Considerando que o Alto Uruguai Catarinense destaca-se, nacionalmente, na produção de carne de suínos avaliou-se a qualidade de lingüiça frescal do tipo toscana, produzida e comercializada na região por meio da quantificação de hidroxiprolina.

\section{MATERIAL E MÉTODOS}

\subsection{AMOSTRAGEM}

As amostras de lingüiça frescal suína do tipo toscana foram coletadas em mercados varejistas, distribuídos em quatro municípios do Alto Uruguai Catarinense, no período entre fevereiro e março de 2006. Foram coletadas 10 amostras de lingüiça de três diferentes procedências com registro de inspeção estadual e federal, totalizando 30 amostras. As amostras adquiridas apresentavam datas de produção diferentes para evitar que produtos do mesmo lote fossem analisados. Após a coleta, o material foi acondicionado em caixas isotérmicas para preservação da qualidade e levado em seguida para os laboratórios da Universidade do Contestado (UnC), Campus Concórdia.

As amostras foram submetidas à retirada das tripas e homogeneizadas em cutter, sendo analisadas no mesmo dia ou armazenadas sob refrigeração por no máximo 24 horas.

\subsection{DETERMINAÇÃO DE HIDROXIPROLINA E COLÁGENO}

Realizou-se a determinação do teor de hidroxiprolina como medida do material colagenoso em carnes e produtos de carne, mediante método referenciado pela AOAC (1995).

Foram pesadas $10 \mathrm{~g}$ da amostra homogeneizada em erlenmeyer e hidrolisada com $\mathrm{H}_{2} \mathrm{SO}_{4} 7 \mathrm{~N}$ em estufa a $105^{\circ} \mathrm{C}$ por 16 horas. A solução ainda quente foi filtrada e diluída, sendo retirada em seguida alíquota de $2 \mathrm{~mL}$ para oxidação com cloramina T. Esse reagente transforma a hidroxiprolina num pirrol, que na presença de 4-dimetilaminobenzaldeído desenvolve coloração vermelho-púrpura com absorção máxima em $560 \mathrm{~nm}$. Preparou-se a curva de calibração utilizando hidroxiprolina (pureza $\geq 99 \%$, MERCK). Todas as determinações colorimétricas foram efetuadas em espectrofotômetro FEMTO 700Plus.

Calculou-se o conteúdo de hidroxiprolina pela seguinte expressão: 
Em que:

$$
\mathrm{OH}-\text { pro }(g / 100 g)=(h \times 2,5) /(m \times V)
$$

$\mathrm{OH}$-pro = conteúdo de hidroxiprolina na amostra;

$h=$ hidroxiprolina, calculada em curva de calibração;

$m=$ peso da amostra;

$V=$ volume tomado da diluição final.

Para o cálculo do conteúdo de colágeno utilizou-se a fórmula:

$$
T C(g / 100 g)=(O H-p r o \times 8)
$$

\subsection{DETERMINAÇÃO DE UMIDADE}

Aproximadamente $5 \mathrm{~g}$ de amostra, previamente homogeneizada, foi levada a estufa a $105^{\circ} \mathrm{C}$ por 3 horas. A amostra resfriada em dessecador foi pesada em intervalos de uma hora até atingir peso constante (IAL, 1985).

\subsection{ANÁLISE DOS DADOS}

Para o tratamento estatístico dos dados utilizou-se o programa Excel (MICROSOFT CORPORATION, 1998), sendo as médias obtidas diferenciadas pelo teste "T". Todas as determinações foram realizadas em duplicata. Os valores de proteína necessários para o cálculo da relação colágeno/ proteínas totais foram obtidos da rotulagem das amostras coletadas.

\section{RESULTADOS E DISCUSSÃO}

As amostras foram identificadas como A, B e C, conforme sua procedência, sendo que as lingüiças toscanas $\mathbf{A}$ e $\mathbf{B}$ continham selo de inspeção federal (SIF) e a lingüiça toscana $\mathbf{C}$ o selo de inspeção estadual (SIE).

Os resultados encontrados para os teores de hidroxiprolina, colágeno e umidade são apresentados na Tabela 1.

\section{TABELA 1 - RESULTADOS DAS MÉDIAS PERCENTUAIS, EXPRESSOS EM BASE SECA, DE HIDROXIPROLINA (OH-PRO), COLÁGENO (TC) E UMIDADE PARA AS AMOSTRAS DE LINGÜIÇA FRESCAL ESTUDADAS}

\begin{tabular}{cccc}
\hline Procedência & OH-pro* & TC $^{*}$ & Umidade $^{*}$ \\
\hline Toscana A (SIF) & $0,29^{\mathrm{b}}$ & $2,36^{\mathrm{b}}$ & $60,21^{\mathrm{b}}$ \\
Toscana B (SIF) & $0,20^{\mathrm{a}}$ & $1,59^{\mathrm{a}}$ & $51,69^{\mathrm{a}}$ \\
Toscana C (SIE) & $0,21^{\mathrm{a}}$ & $1,68^{\mathrm{a}}$ & $53,54^{\mathrm{a}}$ \\
\hline
\end{tabular}

*Letras iguais na mesma coluna indicam médias equivalentes $(p<0,05)$. 
Os resultados de hidroxiprolina obtidos mostraram-se menores que os encontrados em trabalhos realizados com lingüiças suínas inspecionadas no Brasil (FERRÃO, SANTOS e FERRÃO, 2002a) e na Espanha (BELTRÁN et al., 1993), nos quais foram obtidas médias percentuais de 0,50\%. Pode-se admitir que as amostras pesquisadas apresentam boa qualidade, considerando que a presença de hidroxiprolina indica o uso de cortes menos nobres na elaboração desses produtos cárneos. Além disso, não há no Brasil legislação regulamentando a adição de tecido conjuntivo colagenoso em embutidos.

Em relação ao percentual de umidade, todas as amostras atenderam ao padrão recomendado pela legislação para lingüiça frescal (BRASIL, 2000) de no máximo $70 \%$ de umidade.

Considerando as procedências, a amostra $\mathbf{A}$ apresentou percentuais significativamente superiores às amostras $\mathbf{B}$ e $\mathbf{C}$ para todos os parâmetros avaliados.

Em relação ao aspecto nutricional, alguns autores têm assumido que produtos cárneos devem conter no máximo $16 \%$ de colágeno em relação às proteínas totais para alcançar valor nutritivo aceitável (SADLER e YOUNG, 1993 apud REIS et al., 1999). A Tabela 2 apresenta os resultados encontrados para essa relação, apontando boa qualidade nutricional das lingüiças toscanas estudadas.

\section{TABELA 2 - MÉDIA PERCENTUAL DA RELAÇÃO COLÁGENO/PROTEÍNA (TC/P) DAS AMOSTRAS DE LINGÜIÇA TIPO FRESCAL}

\begin{tabular}{cc}
\hline PROCEDÊNCIA & RELAÇÃO TC/P \\
\hline Toscana A (SIF) & 7,64 \\
Toscana B (SIF) & 6,33 \\
Toscana C (SIE) & 6,60 \\
\hline
\end{tabular}

Para avaliar a padronização na produção das amostras estudadas efetuou-se a comparação entre os valores máximos e mínimos para os parâmetros analisados. Aamostra que evidenciou maior diferença na quantidade máxima e mínima de hidroxiprolina foi a lingüiça toscana $\mathbf{A}$, com $0,26 \%$. Tais diferenças para as amostras das procedências $\mathbf{B}$ e $\mathbf{C}$ foram de $0,24 \%$ e $0,11 \%$, respectivamente (Figura 1 ).

\footnotetext{
FIGURA 1 - VALORES MÁXIMOS (口) E MÍNIMOS (口) DE HIDROXIPROLINA PARA AS AMOSTRAS ESTUDADAS
}

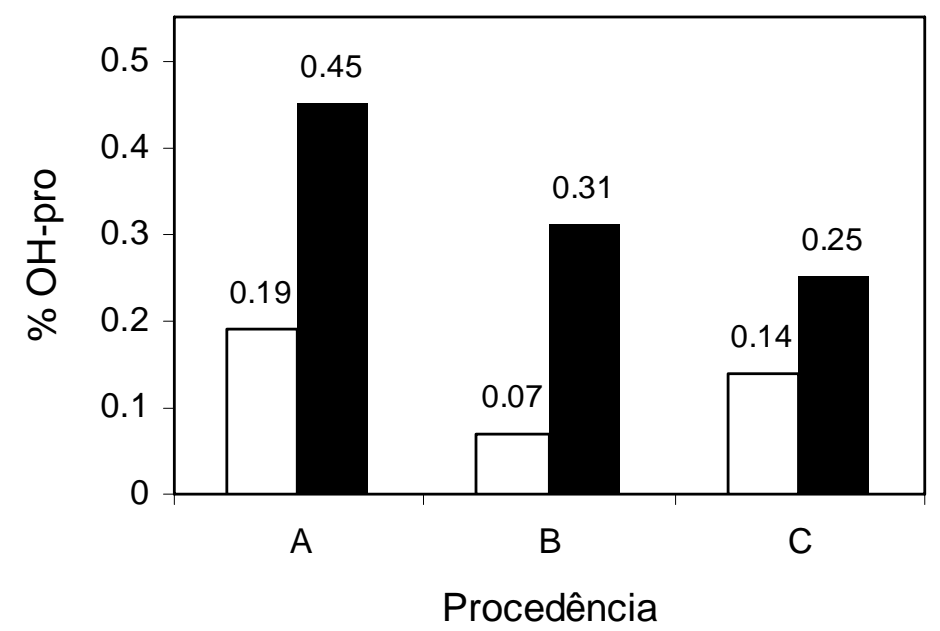


Considerando a procedência das lingüiças para a variabilidade do percentual de umidade (Figura 2), a amostra C destacou-se com 19\% seguida pela amostra B com 10,9\%. A menor variação de umidade $(5,4 \%)$ foi obtida pelas amostras da procedência $\mathbf{A}$.

\section{FIGURA 2 - VALORES MÁXIMOS (ロ) E MÍNIMOS (口) DE UMIDADE PARA AS AMOSTRAS ESTUDADAS}

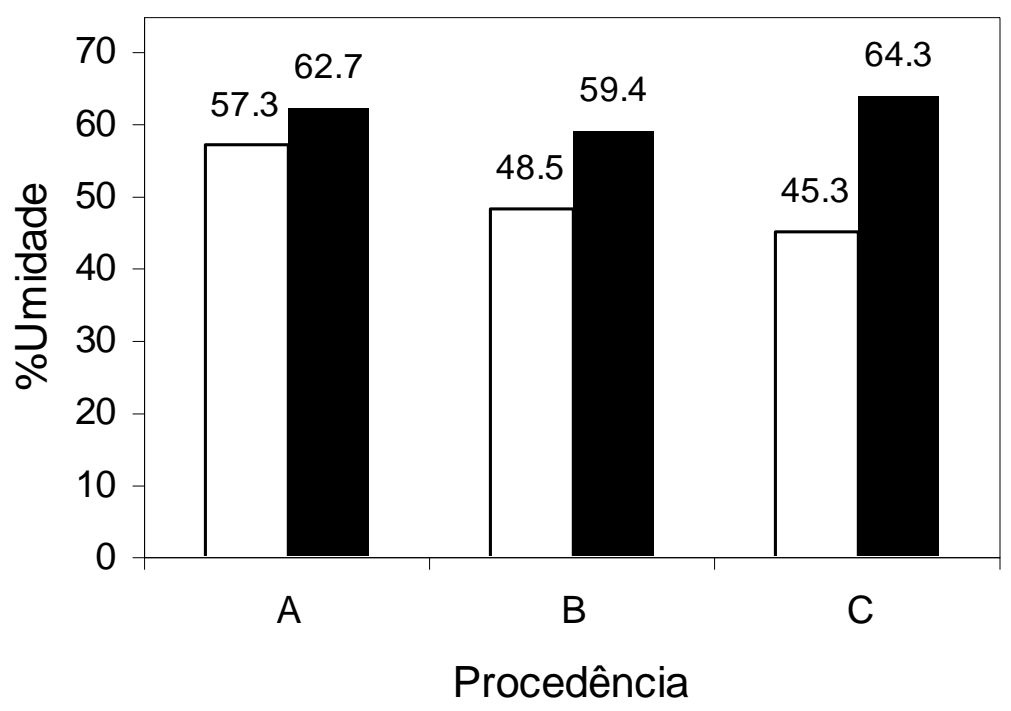

A variação dos valores máximos e mínimos indica que não há padronização dos produtos pesquisados, mas a variabilidade verificada para as amostras quanto ao percentual de hidroxiprolina e umidade foi menor do que a obtida por FERRÃO, SANTOS e FERRÃO (2002a; 2002b) e BELTRÁN et al. (1993).

A variabilidade entre as procedências está relacionada com a matéria-prima utilizada na elaboração das lingüiças. Para a procedência $\mathbf{B}$, a rotulagem das amostras declarava o uso de cortes cárneos apenas de suínos conforme estabelece a legislação para esse tipo de produto. A rotulagem das amostras da procedência $\mathbf{A}$ não informava especificamente os ingredientes utilizados. Já as amostras de lingüiça da procedência $\mathbf{C}$ declaravam em sua rotulagem a utilização de proteína não-cárnea em sua formulação. De acordo com a Instrução Normativa n. 04 (BRASIL, 2000) não é permitida a adição de proteína não-cárnea (como proteína agregada) em lingüiça toscana. Tal fato representa falha do Serviço de Inspeção Estadual (SIE) pelo qual essas amostras deveriam ser fiscalizadas.

\section{CONCLUSÃO}

Os resultados demonstraram que as lingüiças toscanas pesquisadas apresentaram boa qualidade, considerando os aspectos de percentual de hidroxiprolina, colágeno e umidade. Também podem ser consideradas de boa qualidade nutricional e quanto ao controle de processo, pois os valores obtidos na relação colágeno/proteína e de variabilidade são mais adequados que os divulgados pela literatura em trabalho semelhantes.

Nas amostras com selo de Inspeção Estadual foi verificada a irregularidade do uso de proteína não-cárnea declarada em sua rotulagem, sugerindo influência nos resultados das análises dessas amostras e ineficiência no serviço de inspeção. 


\begin{abstract}
FRESH SAUCAGES QUALITY EVALUATION THROUGH HYDROXYPROLINE DETERMINATION

The present study aimed at the estimation of the level of collagen through the determination of hydroxyproline in fresh Toscana sausage commercialized in the region of Alto Uruguai Catarinense, Santa Catarina State, Brazil. The mean levels of hydroxyproline and collagen obtained in this study were significantly higher $(p<0.05)$ in fresh Toscana sausage from the provenience entitled as $A$ when compared with the results of other products analysed. All samples have presented low levels of hydroxyproline in dry basis, with averages of $0.29 \%(\mathrm{~A}), 0.20 \%(\mathrm{~B})$, and $0.21 \%(\mathrm{C})$; and the following average values for collagen: $2.36 \%, 1.59 \%$, and $1.64 \%$, respectively. Results have demonstrated that the Toscana sausages researched in this study present good quality, considering the hydroxyproline, collagen, and humidity percentages. Moreover, these sausages can be considered of good nutritional quality and good process control as the values of the relation collagen/ protein and variability obtained here are better than the ones mentioned by the literature in similar works. However, for one of the proveniences, there were presented irregularities regarding the use of non-fresh derived-protein declared in its label, suggesting influence in the results in relation to this sample as well as inefficiency of the inspection service.
\end{abstract}

KEY-WORDS: TOSCANA SAUSAGE; COLLAGEN; HYDROXYPROLINE; NUTRITIONAL QUALITY.

\title{
REFERÊNCIAS
}

1 ABIPECS. Associação Brasileira da Indústria Produtora e Exportadora de Carne Suína. Suinocultura brasileira. São Paulo, 2006. Disponível em: <http://www.abipecs.org.br/cultura.php> Acesso em: 14 de fev. 2006.

2 AOAC. Association of Official Agricultural Chemists. Official methods of analysis of AOAC International. Arlington, 1995. v. 2.

3 BELTRÁN, J. A.; MARQUINA, P.; RONCALÉS, P.; MORENO, I. J.; PEIRÓ, J. M. Caracterización y diferenciación físicoquímica de los tipos comerciales de la Longaniza de Aragón. Revista Espanõla de Ciencia y Tecnologia de Alimentos, v. 33, n. 6, p. 631-650, 1993.

4 BRASIL. Ministério da Agricultura e do Abastecimento. Secretaria de Defesa Agropecuária. Instrução Normativa n. 4, de 31 de março de 2000. Brasília, DF, 2000.

5 EGELANDSDAL, B.; DIGSTAD, G.; TOGERSEN, G.; LUNDBY, F.; LANGSRUD, O. Autofluorencence quantifies collagen in sausage batters with a large variation in myoglobin content. Meat Science, v. 69, p. 35-46, 2005.

6 FERRÃO, S. P. B.; SANTOS, W. L. M.; FERRÃO, I. Determinação de hidroxiprolina para avaliação da qualidade de lingüiças frescais comercializadas em Belo Horizonte/MG. In: CONGRESSO BRASILEIRO DE CIÊNCIAETECNOLOGIA DE ALIMENTOS, 18., 2002, Porto Alegre, RS. Anais... Porto Alegre: SBCTA, 2002a.

7 FERRÃO, S. P. B.; SANTOS, W. L. M.; FERRÃO, I. Composição físico-química de lingüiças comercializadas em Belo Horizonte/Minas Gerais. In: CONGRESSO BRASILEIRO DE CIÊNCIAE TECNOLOGIA DE ALIMENTOS, 18., 2002, Porto Alegre RS. Anais... Porto Alegre: SBCTA, 2002b.

8 IAL. Instituto Adolfo Lutz. Normas analíticas do Instituto Adolfo Lutz: métodos químicos para análises de alimentos. 3. ed. São Paulo, 1985.

9 MICROSOFT CORPORATION. Microsoft Office Excel 9.0. Redmond, WA, 1998. Planilha eletrônica.

10 PARDI, M. C.; SANTOS, I. F.; SOUZA. E. R.; PARDI, H. S. Ciência, higiene e tecnologia da carne. 2.ed. Goiânia: UFG, 2001.

11 REIS, R. A. A.; SANTOS, W. L. M.; OLIVEIRA, A. L.; SOUZA, R. M.; VELOSO, C.R.V. Quantificação da hidroxiprolina como índice de qualidade de salsicha comercializada em Belo Horizonte - MG. Arquivo Brasileiro de Medicina Veterinária e Zootecnia, v.51, n. 6, p. 589-94, 1999. 